Engeb $\varnothing$ ' A., Skatvedt, Å., and Torp, O. (2019). "Soft Elements in Collaborative Project Delivery Methods" In: Proc. $27^{\text {th }}$ Annual Conference of the International. Group for Lean Construction (IGLC), Pasquire C. and Hamzeh F.R. (ed.), Dublin, Ireland, pp. 773-784. DOI: https://doi.org/10.24928/2019/0192. Available at: <www.iglc.net>.

\title{
SOFT ELEMENTS IN COLLABORATIVE PROJECT DELIVERY METHODS
}

\author{
Atle Engebø ${ }^{1}$, Åsmund Skatvedt ${ }^{2}$, and Olav Torp ${ }^{3}$
}

\begin{abstract}
Lean construction seeks to improve project performance through maximizing value and reducing waste. As a way of improving project performance, collaborative project delivery methods have been presented as a potential solution. The foundation of collaborative PDM is that they seek to align all participants to well understood and agreed on project goals. However, collaborative PDM is more person-dependent than traditional delivery methods. Hence, this paper aims to increase this understanding of soft elements in collaborative PDMs. A qualitative case study was chosen for exploring the phenomena of soft elements in collaborative PDMs. The combination of literature, documents, and interviews was selected as the basis for data collection. The study has identified that collaborative PDM imposes specific demands upon project managers and owner's representatives and that formal elements have a significant impact on the soft elements in the project. Soft elements need to be viewed in light of the delivery method, and as indicators of the continuous relationship between members of the project organisation. Therefore, soft elements such as Top management support, Trust, Shared goals and motivation, Attaining the right people, Openness/transparency were all identified as necessary for such an approach to be successful. A critical success factor for soft elements lies in whether the management has enough resources to continuously follow-up. Especially in regards to which elements being implemented and nourished.
\end{abstract}

\section{KEYWORDS}

Lean construction, culture \& people, soft elements, collaboration, project delivery methods.

\section{INTRODUCTION}

Today's construction industry is both fragmented and specialised as only a few if any, industry actors have the necessary competence in-house to complete projects without involving external specialists or contractors (Oakland and Marosszeky, 2017, pp.3-22). Over the last decades, there has been a focus on streamlining the construction process, by digitalization and innovation. One management movement, Lean Construction (LC), have developed a three-part framework to address the challenges related to modern construction

1 PhD Candidate, NTNU - Norwegian University of Science and Technology, Trondheim, Norway, +47 90571902, atle.engebo@ntnu.no

2 Msc. Civil Engineering, Aase Prosjekt., Oslo, Norway,

3 Associate Professor, NTNU - Norwegian University of Science and Technology, Trondheim, Norway, Olav.Torp@ntnu.no 
that includes 'Operating system' (often referred to as Lean Management methods), 'Commercial,' and 'Organisational.' This paper focuses on the organisational part of the triangle, more specifically as to how to organise to align the interest of the client and the supply-chain (Oakland and Marosszeky, 2017, pp.3-22).

Collaborative project delivery methods are relatively new in the context of the Norwegian construction industry, and the approach is often labelled 'Partnering' (Wøien et al., 2016; Hosseini et al., 2016). The development of the Partnering approach is often attributed to the early nineties and described as a commitment to trust, collaboration, and excellence on the part of all the participants involved in a project (Larson and Gray, 1994). From being mere conceptual, collaborative project delivery has developed into applied methods such as the Australian Alliancing approach (Walker, 2002), and the American Integrated Project Delivery approach (Matthews and Howell, 2005). While many claims that collaborative project delivery methods represent an appealing solution to the challenges of today's industry, this approach also involves challenges.

Success is prescribed to be closely related to the ability to commit to trust, collaboration, and excellence on the part of all the project participants (Pishdad-Bozorgi, 2017; Challender, 2017). The ability to commit to collaboration requires great emphasis on the project's soft elements. Soft elements are, in literature, defined by Cheung et al. (2003) as "(...) behavioural aspects such as trust, honesty, communication, and relationship". Yeung et al. (2007a) define it as "(...) related to the relationship between the people in the project". If hard elements are defined as discrete, quantifiable and easily observed, soft elements exist more towards the qualitative end of the spectrum. Any human interaction will have a degree of trust and honesty, and in many aspects, hard elements are used to support this. Hence, soft elements are best defined as a combination between Cheung et al. (2003) and Yeung et al. (2007) Soft elements are qualitative indicators (e.g., trust, honesty) of the continuous relationship between members of the project organisation.

The interest in collaborative project delivery methods has increased in recent decades. According to the World Value Survey, countries such as Norway, Sweden, and Finland scores among the top on cross-country comparisons of self-reported trust attitudes (Esteban Ortiz-Ospina and Roser, 2019). The open attitude has created opportunities for exploitation within the framework of traditional project delivery in Norway (Lohne et al., 2017; Engebø et al., 2018; Engebø et al., 2016). However, the high level of interpersonal trust in society also constitute an appropriate foundation for adopting collaborative project delivery methods in construction projects. This paper contributes to research on Lean Construction by presenting an empirical investigation into how a public client view and monitors the soft elements in collaborative project delivery projects. The purpose of this study is to investigate soft elements in collaborative project delivery projects through the following research questions:

1. Why do clients use collaborative project delivery methods?

2. What soft elements characterize a collaborative project delivery project?

3. How can clients better facilitate the soft elements in projects?

The research questions have been considered using document analysis, and semi-structured interviews. The document study was used to analyse the internal and public documents 
used in the implementation of partnering. A total of ten semi-structured interviews of project managers working for a large professional public client in Norway were conducted.

\section{METHODOLOGY}

The study took the form of a case study with the intent to report on and explore the phenomena of collaborative project delivery methods through the lens of project managers working for a large professional public client in Norway. The study was initiated by conducting a literature review. The databases used were Oria (The university's electronic literature database), Engineering Village (Compedex), and Google Scholar. Then keywords/ search phrases were selected, for example, "Construction AND success AND soft elements," "partnering AND soft elements." Then, the literature was supplemented with the searches within the IGLC Conference paper Database and the Lean Construction Journal, to identify potential knowledge gap in the lean literature when it comes to soft elements and project delivery methods.

The case study is according to Creswell and Poth (2017) a suitable research design for exploring phenomena using a qualitative approach. Therefore, the combination of documents and interviews were chosen as the basis for data collection. Selecting more than one type of empirical data makes it possible to investigate the research problem through different lenses, which should strengthen the analysis (Yin, 2014). Thus, the document study is included to bring a mean for triangulating the data, providing context and additional empirical evidence into the analysis (Yin, 2014). The data collection was carried out during the Spring of 2018. The interviewees were selected due to their experience and interest in collaborative project delivery, but also because of involvement in introducing, in general, new processes or ways of doing things within their organisation. The initial recruitment was conducted through a contact person provided by the organisation studied, and later through the network of the first interviewees.

A total of 10 interviews were held, where most of the interviewees were project managers, using semi-structured interviews (Kvale and Flick, 2007; Blumberg et al., 2011). A document study was also conducted, analysing documents such as contracts, meeting reports, guidelines, notes, etc. (Yin, 2014; Tjora, 2012). In particular, the document study focussed on the Guideline for using collaborative project delivery methods developed by the Norwegian Contractors Guild, as well as an internal guideline used by the professional public client. The document study was valuable for providing context, especially the 'Internal Guide' gave insight into how collaborative project delivery methods were perceived by the organisation studied.

The approach generated a rich dataset, permitting for the understanding of the phenomenon under study, whilst leaving the participants' perspectives intact, (Leech, 2002). On the other side, the particular approach is demanding for the researcher as it is dependent on the ability to listen, asking sound questions, and follow-up questions (Yin, 2014; Blumberg et al., 2011). Additionally, the in-depth approach implied a small sample size. Thus, the researchers acknowledge that the opportunity to draw broad generalisations from the dataset also is correspondingly limited. In this way, the results must be viewed in the context of the local situations and conditions studied in Norway. 


\section{THEMATIC LITERATURE REVIEW}

The project management literature uses a variety of terms for defining project delivery methods. Wearne (1989) uses the more generic term contract strategy describing the process of procurement and the organizational and contractual policies chosen for the execution of a project. Expanding upon phenomena of contract strategy, this paper adopts the following definition of a project delivery methods: "A system for organizing and financing design, construction, operations and maintenance activities that facilitates the delivery of a good or service" (Miller et al., 2000).

\section{Collaborative Project Delivery methods}

As stated in the introduction, collaborative project delivery have evolved from being a more generic concept (i.e., Partnering), into real-world methods such as the Australian Alliancing approach (Walker, 2002), and the American Integrated Project Delivery approach (Matthews and Howell, 2005). Regardless of the labels used, the same fundamental concept seems to apply, more collaboration between actors and organizations involved in construction projects (Eriksson, 2010; Yeung et al., 2007b). Though the concept has existed for more than 20 years, a consensus regarding the methodology has not been established yet (Eriksson, 2010). Using the term 'Partnering,' Eriksson (2010) identifies the following core components: bid evaluation based on soft parameters, compensation form based on open books, and the usage of start-up workshop, joint objectives, follow-up workshops, teambuilding, and conflict resolution techniques (Eriksson, 2010).

In the lean literature, collaborative project delivery is often labelled Integrated Project Delivery (IPD), also referred to as Lean IPD, IPD-ish, and IPDlite. As with the Australian Alliancing approach, IPD is an approach aimed at aligning project objectives with the interests of key participants (Matthews et al., 2003). IPD has distinguished itself from traditional project delivery by focusing on the so-called Lean Triangle (Alarcón et al., 2013). Thus, the approach seeks to differentiate itself from today's common project design and management practices through emphasising integration in the organisation and process design and management (Fischer et al., 2014). While the IPD method stands out by using a specific contractual arrangement, Partnering and IPD-ish methods seek to imitate the perceived benefits without conflicting with procurement laws- or standards (Kim et al., 2016). This is the case in Norway, where national procurement laws- and standards still are used in collaborative project delivery. As IPD is gaining momentum in the industry, some case studies have started to emerge from around the world. Rached et al. (2014) studied IPD implementation of IPD methods in the Middle East, stating that some cultural barriers specific to the region need to be taken into consideration when implementing IPD methods. Forero et al. (2015) investigated the implementation in Colombia and found that the main barriers were lack of knowledge and information about the IPD methods. As for China, adversarial relationships, legal issues, and lack of owner willingness were perceived to be the main implementation barriers ( $\mathrm{Li}$ and $\mathrm{Ma}$, 2017). In Peru, accountability, trust, and respect needed to be strengthened to create real commitments required for successful implementation of IPD (Gomez et al., 2018). 
In Norway, preliminary findings indicate that projects could benefit from focusing more on building relationships to create a collaborative project culture (Aslesen et al., 2018). Haugseth et al. (2014) describe collaborative project delivery as a way of facilitating a lean construction process where less time is wasted on disputes, and more value is added to the project. The most common collaborative project delivery method is a so-called 'samspillsentreprise' (in Norwegian, it is a variation of IPD), defined as a collaborative delivery method characterised by early involvement of the actors, dialogue, trust, and openness (EBA, 2017). Furthermore, such projects can be organised either as "Collaboration with Design-Build" (in Norwegian, "Samspill til totalentreprise") where the actors collaborate in the development of the project from the programming phase into a pre-project with a target price. Then the contractor takes over the responsibility by signing a Design-Build contract. The second variation, "Collaboration with incentives" (in Norwegian, "Samspill med incitement"), where actors collaborate in the development of the project from the programming phase into a pre-project with a target price. Then, the project is carried out as a billing work, with the agreed allocation of potential over/undercutting of the set target price (as a so-called pain/gain share mechanism, see for example Zimina et al. (2012)).

As described above, collaborative project delivery methods are described in the Lean literature. However, reports regarding soft elements seem somewhat underreported. IPD appear to drive cultural change within participating organisations, including influencing behaviour and attitudes, company processes and working practices (Suttie, 2013). However, the transition to more relational-based approaches also appears to create a new set of challenges. Schöttle and Gehbauer (2013) state that there exists resistance against change in the construction industry, supporting the claim by arguing that people are quite reluctant about the implementation of new strategies and processes such as IPD. Also, traditionally trained project manager seems not to be equipped to deal with the relationship-based approaches that involve early involvement from contractor and specialty trades and strong multi-disciplinary collaboration (Seed, 2014). Similarly, Knapp et al. (2014) discuss the critical role of being the owner's representative and how wrong incentives related to this role can render the entire process to failure. Lastly, IPD projects prerequisite organisations having a culture that easily accommodates change encourages innovation and collaboration, or the other way around, the IPD process may influence the perception of participating organisations (Suttie, 2013).

For example, Kulkarni et al. (2012) state that collaborative project delivery methods produce a more reliable cost outcome for public owners. However, soft elements seem not to be well studied in the context of collaborative project delivery; the literature is often limited to stating that teamwork, transparency, trust, collaboration, communication, etc., are all needed to implement such an approach to project delivery successfully. Furthermore, the literature acknowledges that relationship-based approaches impose specific demands upon project managers and owner's representatives. Thus, expanding upon the statements made by Suttie (2013), Seed (2014) and Knapp et al. (2014), this paper seeks to fill this knowledge-gap by study project managers working as owner's representatives on projects using collaborative project delivery methods. 


\section{RESULTS AND DISCUSSION}

\section{WHY DO CLIENTS USE COLLABORATIVE PROJECT DELIVERY METHODS?}

The interviewees stated that the strategic motivation for choosing a collaborative project delivery method was mainly to involve the contractor in an earlier stage, as well as to increase interaction between all parties involved. In theory, this should set the stage for a win-win situation where the contractor can dictate influence (i.e., lower the risk in the construction phase concurrently as the client is more assured that the contractor understand the overall uncertainties related to the project).

It is often stated that collaborative project delivery methods have a positive impact on the project's performance based on the delivery method's ability to reduce conflict (Oakland and Marosszeky, 2017, p. 101-116; Fischer et al., 2017, p. 365-390). The interviewees were somewhat divided, some agreed, while others argue that it provoked more conflict. However, some explained that while greater openness leads to more disagreement "over the table," the fact that the disputes are brought to the table and discussed in a thorough manner is a positive change. This differs from turnkey contracts, where you send and process change messages. However, neither the interviews nor the document study reveals this as the primary motivation, meaning that the focus is not primarily on improving the relationship between actors in the project. This is reflected in a statement from an interviewee, maintaining that his company does not fear conflict since the company operates in a conflict-laden industry. This idea is further enhanced by the guidelines (internal), where it is explicitly stated that a collaborative project delivery method should be implemented to optimize the design process in regards of time, cost and quality parameters. Thus, the guidelines implicitly state that contractual elements are enough for the creation of the needed collaborative effects.

It was identified that there are significant differences within the organization for choosing to use a collaborative project delivery method. On one side is the result-driven motivation regarding involving the contractor earlier in the project, while on the other hand there is a process-driven motivation through changing the management method from controlling to including.

Although the top management of the organization has general guidelines on how project is to be carried out, the project manager has significant influence as to how to choose to carry them out. This implies that the project manager enjoys a large degree of autonomy when selecting a delivery method, something that naturally creates a large degree of variability regarding project delivery methods within the organization.

For example, in Table 1, we see two project managers and which tools they use to achieve collaboration in the project. Drawing a broad picture, we recognize that project manager 1 wants better and closer collaboration with the participants in the project, while project manager 2 , in line with management guidelines, mainly wants to use a collaborative project delivery method to involve the contractor as early as possible. The effect of the different approach may be the most visible in the construction phase in which project manager 2 choose to enter into a fixed price contract with the contractor and perform the construction phase as a turnkey contract. The interviews indicate that there is a trend 
towards conducting projects with turnkey contracts for the construction phase, i.e., in line with the approach chosen by project manager 2 .

Table 1: Project Management approach to collaboration

\begin{tabular}{lll}
\hline Project Management approach & Project Manager 1 & Project Manager 2 \\
\hline Overall motivation & Closer collaboration & Early contractor involvement \\
Personal involvement in the project & $100 \%$ & One of several projects \\
Contract type & Target Price & Fixed price \\
Relationship with contractor & Transparent & Clear interface/ boundaries \\
Collaboration & Open & Tidy/ orderly \\
\hline
\end{tabular}

\section{WHAT SOFT ELEMENTS CHARACTERIZE A COLLABORATIVE PROJECT DELIVERY PROJECT?}

The literature provides an exhaustive list of soft elements needed for successful collaborative project delivery. The project managers stated through the interviews the following as being the most critical soft elements for collaborative project delivery: Top management support, trust, shared goals and motivation, ownership of the collaboration process, attaining the right people and openness. The project managers believed that a successful collaborative project delivery project started with support from top management, then getting the right people, it then goes into credible involvement of all parties, lastly establishing mutual objectives or mutual understanding, and openness between all involved parties. All these soft elements need to be present to build the trust required. Table 2 summarises the critical soft elements identified through the interviews.

Table 2: key soft elements identified

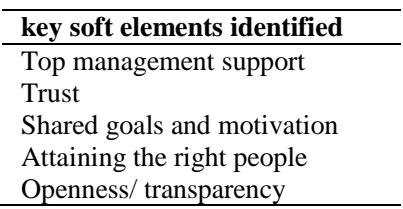

The project managers emphasized the importance of establishing trust between actors in the projects. Trust was thereby described as a basis for being able to carry out the desired collaborative processes. The prerequisite was perceived to be a minimum or rather a credible involvement of all parties, to establish a robust decision-making process. Lack of trust was described through situations where the parties argued for decisions that primarily benefitted themselves or their agenda, not the project. Therefore, without establishing trust between all parties, the project lacks a fundamental principle, often referred to as mutual objectives or mutual understanding.

Furthermore, the project managers described some inter-relation between the soft elements. For example, the relationship between competence and trust was explained through an anecdote about an inexperienced assistant project manager that struggled to obtain the trust of the contractor because the contractor doubted the capability of the assistant project manager. Also, the results show that openness requires established shared goals and motivation, as well as project participants with adequate abilities in communication so that proper communication flow are sustained throughout the project. Furthermore, several of the project managers mention the problem that actors are unable 
to put aside their agendas when developing shared goals for the project. The element shared goals and motivation also depends on a commitment to the collaboration process. The process depends on project participants who want to work for the project as an entity and not just themselves and their mother organization. The project managers maintain that this perspective is person dependent; some seem locked to the traditional way of conducting a project. As emphasised by Cheng and Li (2002), support from top management is crucial for establishing a collaborative environment in every project. However, some of the interviewees stated that top management is often not active or involved on a project level. The establishing of a collaborative environment is therefore almost exclusively initiatedand led by the project manager, giving them an extra dimension of responsibility. This claim is supported by (Larson, 1997), claiming that this is harmful to both the organisation's culture and project delivery.

The study uses the term hard and soft elements. Hard elements are those that are stated in the contract, and that, with- or without intention, contribute towards more collaboration in the project delivery. Soft elements are the so-to-say outcome of either the processspecific tools or methods implemented. Because of this categorisation, another category of elements, "collaborative tools" was introduced, which are those elements that specifically intend to enhance soft elements such as trust, creating ownership, top management support, etc. Thus, the collaborative tools seek to bridge the gap between the contractual (hard) and interpersonal elements (soft). For example, start-up seminars/ workshops are defined as a collaborative tool because it intends to improve the interpersonal relationship between the actors bound to each other in the project through contract.

\section{HOW CAN CLIENTS BETTER FACILITATE FOR THE SOFT ELEMENTS IN PROJECTS?}

As revealed, current practice implicates much responsibility for the project manager. While the organisational guidelines for collaborative project delivery provide a broad framework as to how to conduct collaborative project delivery, the project managers are often left to themselves. This results in the project managers being largely entrusted to themselves in the establishment of specific game-rules for their projects. For the organisation, this leads to a large degree of variability from project to project in their collaborative project portfolio. On the positive side, this approach provides project managers with a large degree of autonomy and influence on their projects as they can coordinate the project in a way that matches their personal qualities as managers. On the negative side, the project managers must use a lot of time and resources to plan and design the project rules- and systems for each project. It was also pointed out that if the project rules- and systems rules were not given enough attention in the project start-up and initial phase, this had the potential to impact the project for a long time negatively. Sometimes such issues had to be solved by bringing in external advisors to clarify and facilitate the project rules.

The study found that clients may gain from following-up the project initiation phase, for example through developing a concise framework and guideline for the establishment of the project organization. As stated by Cheng and Li (2002), the most critical factor in the start-up is support from top management. The project managers interviewed indicated that they were not given enough time at the start of the project to discuss and prepare, 
together with the actors, the form of collaboration needed and wanted. Furthermore, they felt that being just given the formal guideline without proper training, or professional support also contributed negatively. This can be solved using specific collaborative tools such as teambuilding activities, start-up seminar/ workshops or meetings.

Second, the client should implement collaborative tools as an addition to contractual elements to facilitate collaboration. During the interviews, the project managers were challenged about how they follow up on the soft elements. Often the answer was that they did not have specific tools to work with. One of the reasons given to why there is so little focus on soft elements is that they are hard to measure. When asked to provide a rating on trust in their projects using a 5-point Likert scale, some project managers had in-depth answers as to why they gave the score they did while others did not. Some even explained it as a gut-feeling they had. Seen in the light of soft elements existing towards the qualitative end of the spectrum, the lack of a clear explanation seems reasonable.

\section{CONCLUSIONS}

This paper contributes to research on Lean Construction by extending the knowledge about soft elements in collaborative project delivery projects. The study shows that a collaborative project delivery method put specific demands on the client organisation, particularly on how they should view and monitors the soft elements.

The study has identified a wide variety of reasons as to why project managers decide to implement collaborative forms of project delivery methods to their projects. Another critical insight is that contractual elements have a significant impact on the soft elements in the project especially regarding which elements being implemented and nourished. Therefore, soft elements need to be viewed considering the project's overall delivery method. The most prominent soft elements were Top management support, Trust, Shared goals and motivation, Attaining the right people, and finally Openness/transparency. Soft elements are indicators for the relationship and interaction between actors in the project. Thus, they are needed to create and sustain a continuous relationship between members of the project organization, as is the purpose of using a collaborative project delivery method. A critical success factor lies in whether the client's management has enough resources to continuously follow-up. Therefore, the top management should provide the necessary support to the project managers by providing means to use specific collaborative tools such as start-up meetings and workshops and having practically applicable and easily understandable guidelines. The choice between using the "Collaboration with DesignBuild" method as opposed to "Collaboration with incentives" has proven to have a significant impact on the necessity for the project manager's involvement in the project, and thereby, the ability to affect soft elements and project culture. Consequently, such methods should only be chosen if the organisation can assign project managers with the right competence to the project. The right project managers for such projects are those who understand the relationship-aspect of project delivery and have enough time and resources to commit to the project properly. The 'right people' were also described as those who were not too accustomed to the more "rigid" Design-build method. They possess attributes such as being welcoming toward more 'openness' and setting 'common goals.'. 
This research has identified that collaboration is carried out on a different basis, which leads to significant differences in project delivery. Consequently, further research can include other clients as this may identify substantial differences in how various organisations emphasise the importance of soft elements and how this promotes project delivery. Additionally, there is a field open to study the effect specific contractual, organisational and technological elements have on the soft elements.

\section{REFERENCES}

Alarcón, L. F., Mesa, H. \& Howell, G. Characterization of Lean Project Delivery. In: FORMOSO, C. T. \& TZORTZOPOULOS, P., eds. 21th Annual Conference of the International Group for Lean Construction, 2013/07/31 2013 Fortaleza, Brazil. Fortaleza, Brazil, 247-255.

Aslesen, A. R., Nordheim, R., Varegg, B. \& Lædre, O. IPD in Norway. 26th Annual Conference of the International Group for Lean Construction, 2018/07/18 2018 Chennai, India. Chennai, India, 326-336.

Blumberg, B., Cooper, D. R. \& Schindler, P. S. 2011. Business research methods, London, McGraw-Hill Higher Education.

Challender, J. 2017. Trust in collaborative construction procurement strategies. Proceedings of the Institution of Civil Engineers - Management, Procurement and Law, 170, 115-124.

Cheung, S.-O., Ng, T. S. T., Wong, S.-P. \& Suen, H. C. H. 2003. Behavioral aspects in construction partnering. International Journal of Project Management, 21, 333343.

Creswell, J. W. \& Poth, C. N. 2017. Qualitative inquiry and research design: Choosing among five approaches, Sage publications.

EBA 2017. Veileder om samspillsentreprise. https://www.anskaffelser.no/: Entreprenørforeningen-Bygg og Anlegg,

Avdeling for offentlige anskaffelser (Difi).

Engebø, A., Iversen, M. H., Houck, L. D., Lædre, O. \& Lohne, J. 2018. Reputation Management in the AEC-industry after Work-related Crime. Periodica Polytechnica Architecture, 49, 176-184.

Engebø, A., Lohne, J., Rønn, P. E. \& Lædre, O. Counterfeit Materials in the Norwegian AEC-Industry. 2016.

Eriksson, P. E. 2010. Partnering: what is it, when should it be used, and how should it be implemented? Construction Management and Economics, 28, 905-917.

Esteban Ortiz-Ospina \& Roser, M. 2019. Trust [Online]. OurWorldInData.org. Available: https://ourworldindata.org/trust [Online Resource] [Accessed].

Fischer, M., Khanzode, A., Reed, D. \& Ashcraft, H. W. 2017. Integrating project delivery, John Wiley \& Sons.

Fischer, M., Reed, D., Khanzode, D. A. \& Ashcraft, H. A Simple Framework for Integrated Project Delivery. In: KALSAAS, B. T., KOSKELA, L. \& SAURIN, T. A., eds. 22nd Annual Conference of the International Group for Lean Construction, 2014/06/25 2014 Oslo, Norway. Oslo, Norway, 1319-1330. 
Forero, S., Cardenas, S., Vargas, H. \& Garcia, C. A Deeper Look Into the Perception and Disposition to Integrated Project Delivery (IPD) in Colombia. In: SEPPÄNEN, O., GONZÁLEZ, V. A. \& ARROYO, P., eds. 23rd Annual Conference of the International Group for Lean Construction, 2015/07/29 2015 Perth, Australia. Perth, Australia, 297-306.

Gomez, S., Ballard, G., Naderpajouh, N. \& Ruiz, S. Integrated Project Delivery for Infrastructure Projects in Peru. 26th Annual Conference of the International Group for Lean Construction, 2018/07/18 2018 Chennai, India. Chennai, India, 452-462.

Haugseth, N., Lohne, J., Jensen, G. \& Lædre, O. Partnering in Statsbygg. In: KALSAAS, B. T., KOSKELA, L. \& SAURIN, T. A., eds. 22nd Annual Conference of the International Group for Lean Construction, 2014/06/25 2014 Oslo, Norway. Oslo, Norway, 1343-1356.

Hosseini, A., Wondimu, P. A., Bellini, A., HenrikTune, Haugseth, N., Andersen, B. \& Lædre, O. 2016. Project Partnering in Norwegian Construction Industry. Energy Procedia, 96, 241-252.

Kim, Y.-W., Rezqallah, K., Lee, H. W. \& Angeley, J. Integrated Project Delivery in Public Projects: Limitations and Opportunity. 24th Annual Conference of the International Group for Lean Construction, 2016/07/20 2016 Boston, USA. Boston, USA.

Knapp, S., Long, D. \& Howell, G. The Role of the Owner's Representative on IPD Projects. In: KALSAAS, B. T., KOSKELA, L. \& SAURIN, T. A., eds. 22nd Annual Conference of the International Group for Lean Construction, 2014/06/25 2014 Oslo, Norway. Oslo, Norway, 1369-1377.

Kulkarni, A., Rybkowski, Z. K. \& Smith, J. Cost Comparison of Collaborative and IPDLike Project Delivery Methods Versus Competetive Non-collaborative Project Delivery Methods. In: TOMMELEIN, I. D. \& PASQUIRE, C. L., eds. 20th Annual Conference of the International Group for Lean Construction, 2012/07/18 2012 San Diego, USA. San Diego, USA.

Kvale, S. \& Flick, U. 2007. Doing interviews, London, SAGE.

Larson, E. W. \& Gray, C. 1994. Project partnering in the construction industry: The wave of the future? National Productivity Review, 14, 15-24.

Leech, B. L. 2002. Asking questions: techniques for semistructured interviews. Political Science \& Politics, 35, 665-668.

Li, S. \& Ma, Q. Barriers and Challenges to Implement Integrated Project Delivery in China. 25th Annual Conference of the International Group for Lean Construction, 2017/07/09 2017 Heraklion, Greece. Heraklion, Greece, 341-348.

Lohne, J., Svalestuen, F., Knotten, V., Drevland, F. O. \& Lædre, O. 2017. Ethical behaviour in the design phase of AEC projects. International Journal of Managing Projects in Business, 10, 330-345.

Matthews, O. \& Howell, G. A. 2005. Integrated project delivery an example of relational contracting. Lean construction journal, 2, 46-61.

Matthews, O., Howell, G. A. \& Mitropoulos, P. Aligning the Lean Organization: A Contractual Approach. 11th Annual Conference of the International Group for Lean Construction, 2003/01/01 2003 Virginia, USA. Virginia, USA. 
Miller, J. B., Garvin, M., J., Ibbs, C. W. \& Mahoney, S., E. 2000. Toward a New Paradigm: Simultaneous Use of Multiple Project Delivery Methods. Journal of Management in Engineering, 16, 58-67.

Oakland, J. \& Marosszeky, M. 2017. Total construction management: Lean quality in construction project delivery, Routledge.

Pishdad-Bozorgi, P. 2017. Case Studies on the Role of Integrated Project Delivery (IPD) Approach on the Establishment and Promotion of Trust. International Journal of Construction Education and Research, 13, 102-124.

Rached, F., Hraoui, Y., Karam, A. \& Hamzeh, F. Implementation of IPD in the Middle East and its Challenges. In: KALSAAS, B. T., KOSKELA, L. \& SAURIN, T. A., eds. 22nd Annual Conference of the International Group for Lean Construction, 2014/06/25 2014 Oslo, Norway. Oslo, Norway, 293-304.

Schöttle, A. \& Gehbauer, F. Incentive Structure in Public Design-Bid-Build Tendering and Its Effects on Projects. In: FORMOSO, C. T. \& TZORTZOPOULOS, P., eds. 21th Annual Conference of the International Group for Lean Construction, 2013/07/31 2013 Fortaleza, Brazil. Fortaleza, Brazil, 227-236.

Seed, W. R. Integrated Project Delivery Requires a New Project Manager. In:

KALSAAS, B. T., KOSKELA, L. \& SAURIN, T. A., eds. 22nd Annual Conference of the International Group for Lean Construction, 2014/06/25 2014 Oslo, Norway. Oslo, Norway, 1447-1459.

Suttie, J. B. A. The Impacts and Effects of Integrated Project Delivery on Participating Organisations With a Focus on Organisational Culture. In: FORMOSO, C. T. \& TZORTZOPOULOS, P., eds. 21 th Annual Conference of the International Group for Lean Construction, 2013/07/31 2013 Fortaleza, Brazil. Fortaleza, Brazil, 267276.

Tjora, A. H. 2012. Kvalitative forskningsmetoder i praksis, Oslo, Gyldendal akademisk.

Walker, D. H. T. 2002. Enthusiasm, commitment and project alliancing: an Australian experience. Construction innovation, 2, 15-31.

Wearne, S. H. 1989. Control of engineering projects, Thomas Telford.

Wøien, J., Hosseini, A., Klakegg, O. J., Lædre, O. \& Lohne, J. 2016. Partnering Elements' Importance for Success in the Norwegian Construction Industry. Energy Procedia, 96, 229-240.

Yeung, J. F., Chan, A. P. \& Chan, D. W. 2007a. The definition of alliancing in construction as a Wittgenstein family-resemblance concept. International Journal of Project Management, 25, 219-231.

Yeung, J. F. Y., Chan, A. P. C. \& Chan, D. W. M. 2007b. The definition of alliancing in construction as a Wittgenstein family-resemblance concept. International Journal of Project Management, 25, 219-231.

Yin, R. K. 2014. Case Study Research: Design and Methods, Los Angeles, USA, SAGE Publications Inc.

Zimina, D., Ballard, G. \& Pasquire, C. 2012. Target value design: using collaboration and a lean approach to reduce construction cost. Construction Management and Economics, 30, 383-398. 